1 London North West University Healthcare NHS Trust, London, UK

2 Imperial College Healthcare NHS Trust, London, UK

3 Healthwatch Central West London, London, UK

4 Department of Primary Care and Public Health, Imperial College London, London, UK

Correspondence to: T Gardiner thomas.gardiner@nhs.net Cite this as: BMJ 2021;372:n605 http://dx.doi.org/10.1136/bmj.n605 Published: 08 March 2021

\section{Racial and ethnic health disparities in healthcare settings}

\author{
Community organisations have a crucial role in involving under-represented population groups \\ Tom Gardiner, ${ }^{1}$ Sonya Abraham, ${ }^{2}$ Olivia Clymer, ${ }^{3}$ Mala Rao, ${ }^{4}$ Shamini Gnani ${ }^{4}$
}

The precise combination of factors responsible for the disproportionate effect of covid-19 on ethnic minority groups is likely to be complex. However, a clear message from the 4000 stakeholders taking part in Public Health England's review into such ethnic disparities was the need actively to involve diverse and under-represented communities in the process of tackling disparities in health settings. ${ }^{1}$

Our health services can adapt quickly to unprecedented circumstances. Secondary and tertiary care sector providers have built diagnostic, treatment, and protective pathways to accommodate varying levels of covid-19 risk. Primary and outpatient care have adopted an entirely new way of working, with a telephone first and remote consultation model. The research community has also mobilised in a completely new way, with the UK initiating and leading some of the world's major covid-19 vaccine and therapeutic trials.

\section{Varying degrees of trust}

A Wellcome Trust survey found, however, that just $57 \%$ of people from black and Asian ethnic groups had either "complete" or "a great deal of" trust in covid-19 scientific advice, compared with $75 \%$ of people from white backgrounds. ${ }^{2}$ Information on how to minimise the risk of getting or spreading covid-19 was also less clear to people from black and Asian ethnic groups $-52 \%$ compared with $71 \%$ of white people. This finding was reinforced by Public Health England's review, which acknowledged how official guidance and messages about covid-19 were conflicting and difficult to interpret. ${ }^{1}$

The concern is that covid-19 research will follow the historical trend of under-representation of ethnic minorities in clinical and public health studies. ${ }^{3}$ Last year, The BMJ's special issue on racism in medicine underlined how gaps in routine data, national surveys, and commissioned research lead to neglect in UK policy because evidence on how to meet the health needs of ethnic minority groups is inadequate. ${ }^{45}$ This is echoed in recent concerns of under-representation of ethnic minority groups in covid-19 therapeutic and vaccine trials, adding further urgency to tackling this problem. ${ }^{67} \mathrm{An}$ editorial in The BMJ called for a "culturally competent" vaccination programme, highlighting the increased prevalence of vaccine hesitancy among ethnic minority groups. ${ }^{7}$

As we rebuild after covid-19 we must include marginalised groups in health service transformation and medical research. Community organisations hold the key to understanding and tackling racial and ethnic health disparities, and Healthwatch England, with its 151 subsidiary local organisations, offers a nationally replicable model for achieving this objective. Healthwatch's statutory responsibility to engage with local people in designing health and care services should be extended to public health campaigns and research. For example, Healthwatch Central West London has helped National Institute for Health Research (NIHR) clinical research networks to reach out to diverse groups in their community based covid-19 research and has held focus groups to understand the unique experiences of specific ethnic minority groups, avoiding a homogenous approach to ethnicity. ${ }^{8}$

Community organisations established with specific ethnic groups in mind also have a vital role. Responding to poor engagement with talking therapies for mental health problems among black people in the London Borough of Lambeth, local community partnership Black Thrive conducted a survey showing the need for support from black therapists with lived experience of racism and discrimination. ${ }^{9}$ The organisation is now piloting "healing spaces" led by black people and will share its findings with Lambeth's mental health services.

The recently established NIHR Race Equality Public Action Group aims to give ethnic minority communities a stronger voice in shaping research and its practical applications. ${ }^{10}$ It is hoped that the group will have the opportunity to democratise public participation, partly through involving community organisations. Furthermore, equalities minister Kemi Badenoch recently announced a £25m (€29m; \$35m) "community champions" scheme to improve the reach of official public health guidance and other messaging about coronavirus into specific places and groups most at risk from covid-19. ${ }^{11}$ She

acknowledged that local councils are best placed to engage local communities.

\section{Funding is key}

But we cannot expect community organisations to tackle the immense challenges ahead if no effort is made to reverse the damaging effects of a decade's worth of funding cuts. ${ }^{12}$ Last year, in a letter to the secretary of state for health and social care, the chair of Healthwatch England, Robert Francis QC, described how the "network's resources continue to shrink and in some areas are becoming unviable," risking "stifling the voice of health and care users." 13

Despite evidence of the health system's failure to involve people from ethnic minority groups, and multiple national reviews calling for better community engagement as key to tackling disparities, we are yet to see substantial levels of tangible, financial commitment to improve inclusion. The potential of community organisations can be fully 
harnessed only if there is "buy-in" from local health and social care partners. All researchers and healthcare professionals have a duty to ensure that research and health service design involve the communities they intend to serve.

Competing interests: We have read and understood BMJ policy on declaration of interests and have no relevant interests to declare.

Provenance and peer review: Not commissioned, not externally peer reviewed.

1 Public Health England. Beyond the data: understanding the impact of COVID-19 on BAME groups. 2020. https://assets.publishing.service.gov.uk/government/uploads/system/uploads/attachment_data/file/892376/COVID_stakeholder_engagement_synthesis_beyond_the_data.pdf

2 Wellcome Trust. BAME people's experience of British lockdown significantly worse, Wellcome survey finds. Press release, 27 Aug 2020. https://wellcome.org/press-release/bame-peoplesexperience-british-lockdown-significantly-worse-wellcome-survey-finds

3 Treweek S, Forouhi NG, Narayan KMV, Khunti K. COVID-19 and ethnicity: who will research results apply to? Lancet2020;395:1955-7. doi: 10.1016/S0140-6736(20)31380-5 pmid: 32539937

4 Bécares L, Kapadia D, Nazroo J. Neglect of older ethnic minority people in UK research and policy. BMJ 2020;368:m212. doi: 10.1136/bmj.m212 pmid: 32046975

5 Salway S, Holman D, Lee C, etal. Transforming the health system for the UK's multiethnic population. BMJ 2020;368:m268. doi: 10.1136/bmj.m268 pmid: 32047065

6 Gardiner T, Cooke G, Fidler S, Cooper N, Young L. The under-representation of BAME patients in the covid-19 Recovery trial at a major London NHS Trust. J Infect 2020:S0163-4453(20)30699-X. [Epub ahead of print]. doi: 10.1016/j.jinf.2020.11.004. pmid: 33189774

7 Hanif W, Ali S, Patel K, Khunti K. Cultural competence in covid-19 vaccine rollout. BM 2020;371:m4845. doi: 10.1136/bmj.m4845

8 Healthwatch Central West London. Insights from BAME communities in central west London. 2020.

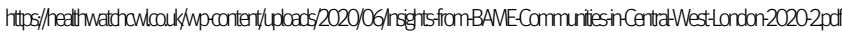

9 Black Thrive. Black Thrive community therapeutic fund. https://www.blackthrive.org.uk/donate3/

10 NIHR. NIHR establishes a race equality public action group. 20 Oct 2020. https:/www.nihr.ac.uk/news/nihr-establishes-a-race-equality-public-action-group/25929

11 Government Equalities Office. Minister for equalities sets out government action to tackle Covid disparities. Press release, 22 Oct 2020. https:/www.gov.uk/government/news/minister-forequalities-sets-out-government-action-to-tackle-covid-disparities

12 Healthwatch. State of support: funding for local Healthwatch 2019/20. https://www.healthwatch.co.uk/sites/healthwatch.co.uk/files/20200205\%20State\%20of\%20Support\%20201920_0.pdf

13 Healthwatch. Letter to the Rt Hon Matthew Hancock MP Secretary of State for Health and Social Care. 2020. https://www.healthwatch.co.uk/sites/health-

watch.co.uk/files/20200205\%20State\%20of\%20Support\%20Letter\%20to\%20SoS.pdf 